\title{
Design of Fractional Order PID controller using Soft computing methods for a Buck-Boost converter
}

\author{
J.Poovarasan ${ }^{1}$, R.Kayalvizhi ${ }^{2}$, R.K.Pongiannan ${ }^{3}$ \\ ${ }^{1}$ (Department of EEE, Pondicherry Engineering College, Pondicherry, INDIA) \\ ${ }^{2}$ (Department of Instrumentation Engg, Annamalai University, Annamalai Nagar, Tamil Nadu, INDIA) \\ ${ }^{3}$ (Department of EEE, Avvaiyar College of Engg \& Tech for Women, Pondicherry, INDIA)
}

\begin{abstract}
Fractional order controller is widely used in most areas of science and engineering, being recognized its ability to yield a superior control in many dynamical systems. This work proposes the applications of a Fractional Order PID (FOPID) controller in the area of Power Electronics for a DC-DC power converter to evaluate the use of Fractional Order PID controller with soft computing techniques. To design Fractional Order PID controller is to determine the two important parameters $\lambda$ (integrator order) and $\mu$ (derivative order). In this article that the response and performance of Fractional Order PID controller is compared with closed loop conventional PID controller. In all the cases the Fractional Order PID controller much better than conventional PID controller for the given system.
\end{abstract}

Keywords:- Conventional PID, Cuckoo search, DC-DC converter, FOPID, Particle Swarm optimization

\section{INTRODUCTION}

Basically, the DC-DC converter consists of the power semiconductor devices which are operated as electronic switches and classified as switched-mode DC-DC converters or normally refers as Switched mode power supply. Operation of the switching devices causes the inherently nonlinear characteristic of the BuckBoost converters. Due to this unwanted nonlinear characteristics, the converters requires a controller with a high degree of dynamic response. Recently, the research on the switching control techniques has been highlighted in order to achieve a high-quality power system [1].

In the past decade, the controller for the PWM switching control is restraining to Proportional-IntegralDifferential (PID) controller. This controller often applied to the converters because of their simplicity. However, implementations of this control method to the nonlinear plants such as the power converters will undergo from dynamic response of the converter output voltage regulation. In general, PID controller produces long rise time when the overshoot in output voltage decreases [2]. In order to tackle this problem and improve the dynamic response of DC-DC converters, a Fractional Order PID controller has been used. The design aspects of the controllers based on several soft computing techniques. A Fractional Order PID controller has been used to regulate the output DC voltage of a Buck-Boost converter within a specified tolerance limit. A very important aspect of designing FOPID controllers is to decide upon the values of $\mathrm{K}_{\mathrm{P}}, \mathrm{K}_{\mathrm{i}}, \mathrm{K}_{\mathrm{d}}, \lambda$ and $\mu$. The Cuckoo search and Particle Swarm Optimization Algorithms are used for tuning the FOPID controller. Fractional order dynamic systems and controllers have been increasing in interest in many areas of science and engineering in the last few years. Controllers consisting of fractional order derivatives and integrals have been used in industrial applications such as power electronics [3], system identification [4], robotic manipulators [5], etc., It should be noted that there are a growing number of physical systems whose behaviour can be compactly determined using the fractional order system theory and can be controlled with Fractional Order ProportionalIntegral-Derivative (FOPID) controllers [6].

The present work deals with the design and control implementation of a Buck- Boost DC-DC power converter. DC-DC power converters are employed in order to transform an unregulated DC voltage input to regulated output voltage. The contribution of this work consists mainly in the design of $\mathrm{K}_{\mathrm{P}}, \mathrm{K}_{\mathrm{i}}, \mathrm{K}_{\mathrm{d}}, \lambda$ and $\mu$ values are finding using Cuckoo search optimization and Particle swarm optimization technique to design the Fractional order PID controller and compared with conventional one. The development and implementation of the proposed controller was done using MATLAB/Simulink.

\section{CONVERTER TOPOLOGY}

Fig.1 show the circuit topology of Buck-Boost converter. The Buck-Boost converter is a type of stepdown and step-up DC-DC converter [7]. Output of the Buck-Boost converter is regulated according to the duty cycle of the PWM input at fixed frequency. When the duty cycle (d) is less than 0.5 , the output voltage of converter is lower than the input voltage. On other condition, when the duty cycle is more than 0.5 the output voltage of converter is higher than the input voltage. The basic circuit of a Buck-Boost converter is illustrated in 
Fig.1 where $V_{\text {in }}$ is input voltage source, $V_{o}$ is output voltage, $\mathrm{Sw}$ is switching component, $\mathrm{d}$ is diode, $\mathrm{C}$ is capacitance, $\mathrm{L}$ is inductor windings and $\mathrm{R}$ is load resistance.

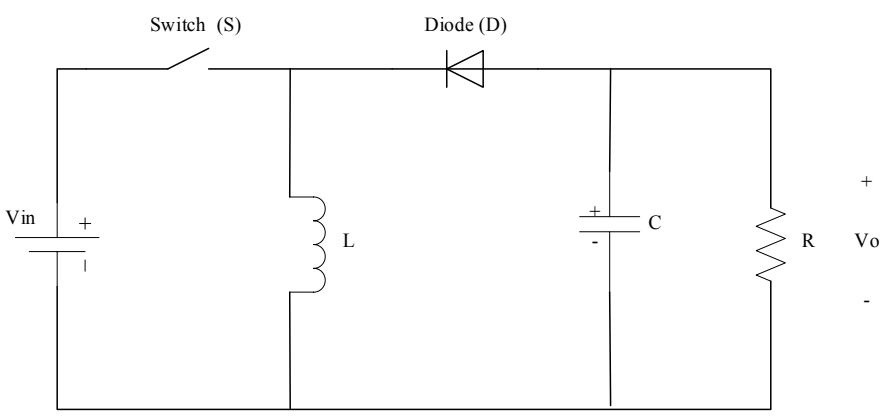

Fig .1 Circuit topology of buck-boost converter

The transfer function of buck-boost converter is given by [7]

$$
G(s)=\frac{-D^{\prime} R}{L R C s^{2}+L s+D^{\prime 2} R}
$$

\section{FRACTIONAL ORDER $P I^{\lambda} D^{\mu}$ CONTROLLER}

The most common form of a fractional order PID controller is the $\mathrm{PI}^{\lambda} \mathrm{D}^{\mu}$ controller involving an integrator of order $\lambda$ and a differentiator of order $\mu$ where $\lambda$ and $\mu$ can be any real numbers. The transfer function of such a controller has the form

$$
\mathrm{G}_{\mathrm{C}}(\mathrm{s})=\frac{\mathrm{U}(\mathrm{S})}{\mathrm{E}(\mathrm{S})}=\mathrm{k}_{\mathrm{p}}+\mathrm{k}_{\mathrm{I}} \frac{1}{\mathrm{~S}^{\lambda}}+\mathrm{k}_{\mathrm{D}} \mathrm{S}^{\mu},(\lambda, \mu>0)
$$

Where $G c(s)$ is the transfer function of the controller, $E(s)$ is an error, and $U(s)$ is controller's output. The integrator term is $1 \mathrm{~s}^{\lambda}$, that is to say, on a semi-logarithmic plane, there is a line having slope $20^{\lambda} \mathrm{dB} /$ decade. The control signal $\mathrm{u}(\mathrm{t})$ can then be expressed in the time domain as

$$
\mathrm{u}(\mathrm{t})=\mathrm{k}_{\mathrm{p}} \mathrm{e}(\mathrm{t})+\mathrm{k}_{\mathrm{I}} \mathrm{D}^{-\lambda} \mathrm{e}(\mathrm{t})+\mathrm{k}_{\mathrm{D}} \mathrm{D}^{\mu} \mathrm{e}(\mathrm{t})
$$

Fig. 2 show the block-diagram configuration of FOPID. Clearly, selecting $\lambda=1$ and $\mu=1$, a classical PID controller can be recovered. The selections of $\lambda=1, \mu=0$, and $\lambda=0, \mu=1$ respectively corresponds conventional PI \& PD controllers. All these classical types of PID controllers are the special cases of the fractional $\mathrm{PI}^{\lambda} \mathrm{D}^{\mu}$ controller given by (2).

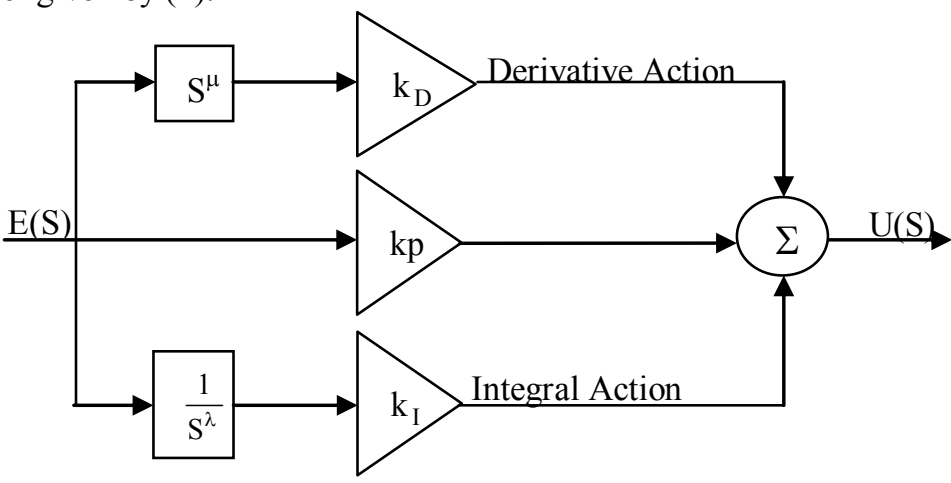

Fig. 2 Block diagram configuration of Fractional Order PID controller

It can be expected that the $\mathrm{PI}^{\lambda} \mathrm{D}^{\mu}$ controller may enhance the systems control performance. One of the most important advantages of the $\mathrm{PI}^{\lambda} \mathrm{D}^{\mu}$ controller is the better control of dynamical systems, which are described by fractional order mathematical models [9]. Another advantage lies in the fact that the $\mathrm{PI}^{\lambda} \mathrm{D}^{\mu}$ controllers are less sensitive to changes of parameters of a controlled system.

\section{PARTICLE SWARM OPTIMIZATION}

PSO is an evolutionary computational technique based on the movement and intelligence of swarms looking for the most fertile feeding location. A "swarm" is an apparently disorganized collection (population) of moving individuals that tend to cluster together, while each individual seems to be moving in a random direction. PSO uses a number of agents (particles) that constitute a swarm moving around in the search space looking for the best solution [10-12]. 
Each particle is treated as a point in an n-dimensional space and adjusts its "flying" according to its own flying experience, as well as the flying experience of other particles. Each particle keeps track of its coordinates in the problem space, which are associated with the best solution (fitness) that has been achieved so far. This value is called pbest. Another best value called gbest is that obtained so far by any particle in the neighbours of the particle. The PSO concept consists of changing the velocity (or acceleration) of each particle toward its pbest and the gbest position at each time step. Each particle tries to modify its current position and velocity according to the distance between its current position and pbest, and the distance between its current position and the gbest. At each step n, by using the individual best position, pbest, and global best position, gbest, a new velocity for the $\mathrm{i}^{\text {th }}$ particle is updated by,

$$
V_{i}=x\left(V_{i}(n-1)+\varphi_{1} r_{1}\left(\text { pbest }_{i}-P_{i}(n-1)\right)+\varphi_{2} r_{2}\left(\text { gbest }-P_{i}(n-1)\right)\right)
$$

\section{CUCKOO SEARCH OPTIMIZATION}

The basic Cuckoo Search (CS) Optimization algorithm [13] is primarily based on the natural obligate brood parasitic behavior of some cuckoo species in combination with the Lévy flight behavior of some birds and fruit flies. Cuckoos are naturally fascinating birds because of their lovely sound they produce and because of their intelligent reproduction strategy. Cuckoos lay their egg in the nest of other host birds, they also tend to destroy others egg to increase the hatching probability of their own egg so that when the eggs are hatched their chicks are fed by the other birds. Some species of cuckoo mimic the nature of host birds so that the host could not recognize them and give the cuckoo better chance of survival. If the host bird identifies the cuckoo egg despite all efforts of cuckoo, the host may either destroy the cuckoo egg or abandon the nest and build a new nest somewhere else. In cuckoo search algorithm cuckoo egg represents a potential solution to the design problem which has a fitness value.

The pseudo code for CS algorithm [14] is:

Start

Objective function $\mathrm{f}(\mathrm{x}), \mathrm{x}=\left(\mathrm{x}_{1}, \mathrm{x}_{2} \ldots \mathrm{x}_{\mathrm{n}}\right)^{\mathrm{T}}$

Generate initial population of $n$ host nests $\mathrm{x}_{\mathrm{i}}(\mathrm{i}=1,2 \ldots \mathrm{n})$

While ( $<$ Max Generations) or (stop criterion)

Move a cuckoo randomly via Lévy flights

Evaluate its fitness $F_{i}$

Randomly choose nest among $n$ available nests (for example $\mathrm{j}$ )

If $\left(F_{i}>F_{j}\right)$ Replace $j$ by the new solution;

Fraction $\mathrm{P}_{\mathrm{a}}$ of worse nests is abandoned and new nests are being built;

Keep the best solutions or nests with quality solutions;

Rank the solutions and find the current best

End while

Post process and visualize results

End

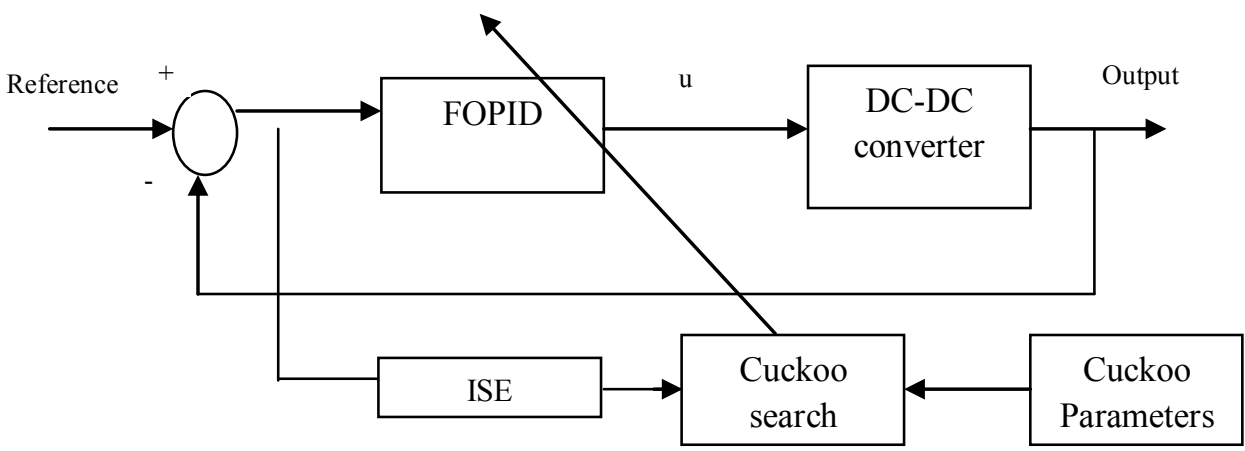

Fig. 3 Block diagram configuration of Fractional Order PID controller

VI.

\section{SIMULATION RESULTS}

The converter was identified by the training data generated by using Particle Swarm Optimization and Cuckoo search algorithm. The Parameters for the converter is given in Table.1. Applying KCL and KVL the transfer function model of the system has obtained. The input to output transfer function of the system is [8]

$$
\frac{V_{o}(s)}{V_{\text {in }}(s)}=-\frac{-3 e 10}{1000 s^{2}+2 e 6 s+2 e 18}
$$


The Controller to output transfer function

$$
\frac{V_{o}(s)}{V_{d}(s)}=-\frac{1.5 e 12 s-2.5 e 16}{1.667 e 8 s^{2}+3.33310 s+3.333 e 14}
$$

For simplification purpose the higher order system can be reduced into

$$
\frac{V_{o}(s)}{V_{d}(s)}=-\frac{1.97}{3,21 e^{-4} s+1} e^{-3.21 s}
$$

Using equation (7) PSO and Cuckoo search algorithm with the parameter mentioned in Table 2 and 3 was implemented for the cost function (ISE) of J. Obtained results shown in table 4. From that it's clearly seen that the FOPID controller was twice fast as PID controller with no oscillation at all.

Where

$$
J=\int_{0}^{t} e(t)^{2} d t
$$

After this, we analysis $\lambda$ and $\mu$ values and applied to the Fractional Order PID Controller of the buck-boost converter to verify the response of the controller. The stability of the system is verified with introduction of $20 \%$ line disturbance. For PSO with $20 \%$ disturbance at $0.05 \mathrm{sec}$ and for Cuckoo search with $20 \%$ disturbance at $0.015 \mathrm{sec}$. it's clear that the Figs.4,5,6 and 7 show the FOPID controller has better and quicker response than PID controller. All the simulations have been carried out in the MATLAB / SIMULINK software.

Table.1.Converter Parameters

\begin{tabular}{|c|c|}
\hline Parameter & Value \\
\hline Vin & 12 Volts \\
\hline R & $10 \Omega$ \\
\hline L & $160 \mu \mathrm{H}$ \\
\hline C & $500 \mu \mathrm{F}$ \\
\hline D & 0.6 \\
\hline Fs & $50 \mathrm{kHz}$ \\
\hline
\end{tabular}

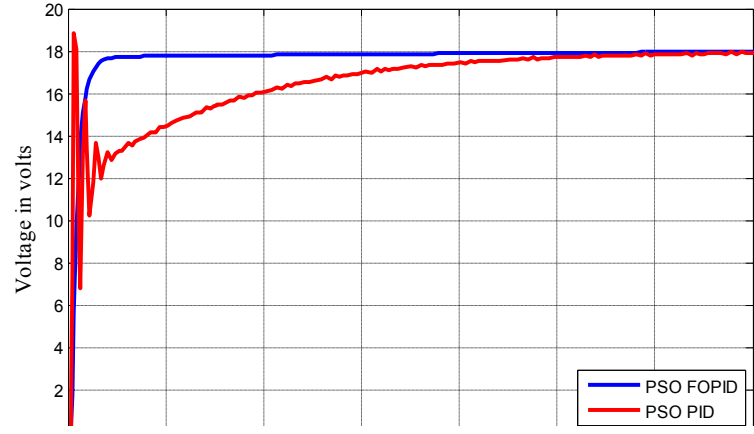

Fig.4.Buck-boost converter with PID and FOPID controller using PSO algorithm

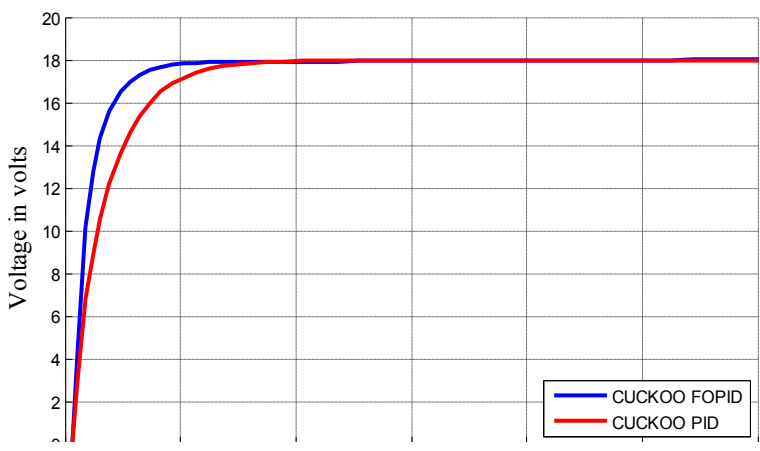

Fig.6.Buck-boost converter with PID and FOPID controller using Cuckoo algorithm

\begin{tabular}{|c|c|}
\hline \multicolumn{2}{|c|}{ Table.2.PSO Parameters } \\
\hline PSO Parameter & Value \\
\hline Number of particles & 10 \\
\hline Number of iteration & 30 \\
\hline Weight & 1 \\
\hline Moment of inertia & 1.5 \\
\hline Velocity & {$[-55]$} \\
\hline
\end{tabular}

Table.3.Cuckoo Parameters

\begin{tabular}{|c|c|}
\hline Cuckoo Parameters & Value \\
\hline Number of nests & 10 \\
\hline Number of iteration & 30 \\
\hline Beta & 1.5 \\
\hline Probability & 0.25 \\
\hline
\end{tabular}

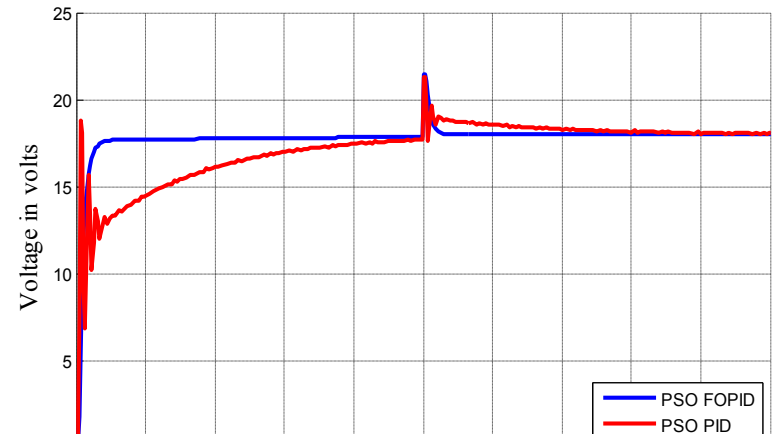

Fig.5.Buck-boost converter with PID and FOPID controller using PSO algorithm with $20 \%$ disturbance

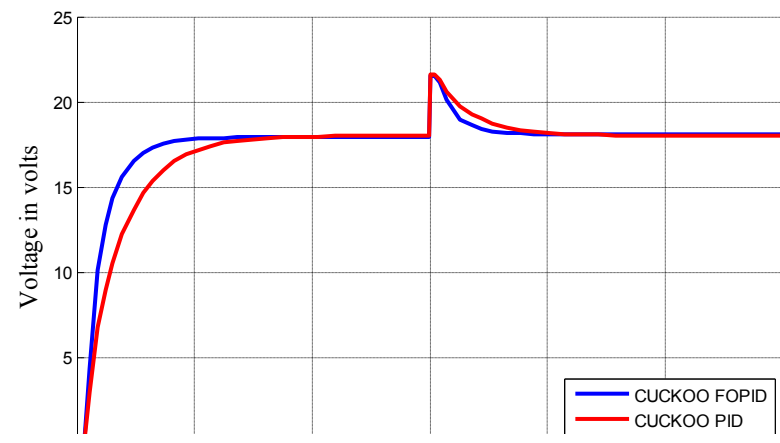

Fig.7.Buck-boost converter with PID and FOPID controller using Cuckoo algorithm with $20 \%$ disturbance 
Table.4 Performance and analysis of Buck-boost converter with PID and FOPID using PSO and Cuckoo algorithms

\begin{tabular}{|c|c|c|c|c|c|c|c|c|c|}
\hline Controller & \multicolumn{5}{|c|}{ Controller Parameters } & $\begin{array}{c}\text { Peak } \\
\text { time } \\
\text { sec }\end{array}$ & $\begin{array}{c}\text { Maximum } \\
\text { overshoot } \\
\% \mathrm{MP}\end{array}$ & $\begin{array}{c}\text { Settling } \\
\text { time } \\
\text { sec }\end{array}$ & Cost \\
\hline PSO PID & 0.8758 & 84.0127 & $7 \mathrm{e}-4$ & - & - & 0.0006 & 4.55 & 0.07 & 85.1225 \\
\hline PSO FOPID & 0.1844 & 77.4486 & 0.2318 & 1.99 & 0.6 & - & - & 0.035 & 48.2970 \\
\hline Cuckoo PID & 0.1421 & 287.4465 & $1.24 \mathrm{e}-4$ & - & - & - & - & 0.01 & 34.2731 \\
\hline $\begin{array}{c}\text { Cuckoo } \\
\text { FOPID }\end{array}$ & 0.1987 & 71.6556 & 1.1 & 1.99 & 0.6 & - & - & 0.005 & 26.9698 \\
\hline
\end{tabular}

VII.

CONCLUSION

This paper presented a smart optimization method for Fractional Order PID controller tuned with Cuckoo Search Optimization. In order to appraise the performance of the controller, the DC-DC buck-boost converter was done with MATLAB/Simulink. The robust design of the Fractional Order PID controller is difficult to compare to the PID controller, since the FOPID controller includes more parameters. All of the parameters related to the FOPID controller were determined using PSO and Cuckoo search optimization. The performance of Cuckoo based FOPID and the PSO based FOPID was compared. Considering all of the results from the simulation, the Cuckoo based FOPID controller can achieve good performance and robustness, superior to those obtained with other one. Moreover, Cuckoo search can achieve faster search speed and better solutions compared to the others. In addition, the Cuckoo - FOPID controller enhanced the flexibility and stability of the PID controller.

\section{REFERENCES}

[1] J. Alvarez-Ramirez, I. Cervantes, G. Espinosa-Perez, P. Maya, and A. Morales, A stable design of PI control for DC-DC converters with an RHS zero, IEEE Trans. Circuits Syst. I, Fundam. Theory Appl., 48(1), 2001, 103-106.

[2] B.M. Vinagre, C.A. Monje, A.J. Calder'on, J.I. Suarez, Fractional PID controllers for industry application: a brief introduction, Journal of Vibration and Control, 13(),2007,1419-1429.

[3] A.J. Calder'on, B.M. Vinagre, V. Feliu, Fractional order control strategies for power electronic buck converters, Signal Processing, 86(), 2006, 2803-2819.

[4] M. Schlegel, M.ech, Fractal system identification for robust control - the moment approach, Proceedings of the 5th International Carpathian Control Conference, 2004, 2004.

[5] N.M. Fonseca Ferreira, J.A. Tenreiro Machado, Fractional-order hybrid control of robotic manipulators, $11^{\text {th }}$ International Conference on Advanced Robotics, 2003, 393-398.

[6] I. Podlubny, Fractional-order systems and $\mathrm{PI}^{\lambda} \mathrm{D}^{\mu}$ controllers, IEEE Transactions on Automatic Control, 44(), 1999, 208-214.

[7] M.H. Rashid, Power Electronics: Circuits, Devices and Applications (Prentice-Hall, Second edition, USA, 1993)

[8] Erickson, Robert W. Fundamentals of Power Electronics. Second Edition. Kluwer, 2004.

[9] C.A.Monje, Y.Q.Chen, B.M.Vinagre,D.Xue, V.Feliu, Fractional order systems and controls, ISSN 1430 - 9491, Springer London Dordrecht Heidelberg newyork, 2010

[10] F.L. Lewis, D.M. Dawson, C.T. Abdallah, Control of Robot Manipulators, New York, Macmillan, 1993.

[11] J. Kennedy, R.C. Eberhart, Y. Shi, Swarm Intelligence, New York, Morgan Kaufmann, 2001.

[12] R.C. Eberhart, J. Kennedy, "A new optimizer using particle swarm theory”, Proceedings of the Sixth International Symposium on Micro Machine and Human Science, pp. 39-43, 1995.

[13] Yang, X.S.; Deb, S. Engineering Optimization by Cuckoo Search, International Journal of Mathematical Modelling and Numerical Optimization, 1(4), 2010, 330-343.

[14] Bacanin, N. Implementation and performance of an object-oriented software system for cuckoo search algorithm, International Journal of Mathematics and Computers in Simulation, 1(6), 2012, 185-191.

\section{AUTHOR BIOGRAPHY}

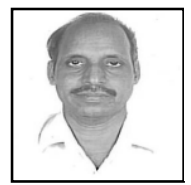

J.Poovarasan was born in Pondicherry, India. He has obtained M.E (Electronics and Instrumentation) from Annamalai University, Chidambaram in 2004. Currently he is pursuing his Ph.D in Annamalai University, Chidambaram in the Department of Electronics and Instrumentation. His areas of interest are power converters, controllers design and applications.

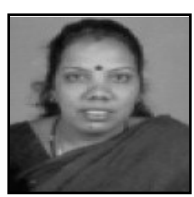

R.Kayalvizhi was born in chidambaram, India, on 1963. She has obtained B.E (Electrical and Instrumentation) and M.E (Power Systems) in 1984 and 1988 respectively from Annamalai University. She completed Ph.D in same university on intelligent control strategies. She has put in a total service of more than 25 years. Her research interests are in DC-DC converter modelling. simulation and imblementation.

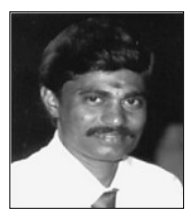

R. K. Pongiannan obtained B.E. degree from CIT, Coimbatore, India, in 1995, M.E. degree from the PSG Tech, Coimbatore, in 2004 and Ph.D from Jawaharlal Nehru Technological University Hyderabad, India, in 2010. Currently, He is a Professor/EEE, Avvaiyar College of Engg \& Tech for Women, Pondicherry, India. He is the author or coauthor of more than 30 papers in international journals and conferences. He is a Reviewer for IEEE TRANSACTIONS ANDINDER SCIENCE JOURNALS. His research interests include power electronics \& drives. 